Dicle Üniversitesi Veteriner Fakültesi Dergisi
https://dergipark.org.tr/tr/pub/duvetfd
$\begin{gathered}\text { Araştırma Makalesi/Research Article } \\ \text { Dicle Üniv Vet Fak Derg 2021;14(1):7-10 } \\ \text { DOI: 10.47027/duvetfd.848303 }\end{gathered}$ $\begin{gathered}\text { e-ISSN:1308-0679 } \\ \text { ISSN:1307-9972 }\end{gathered}$

\title{
Farklı Kanatlı Türlerine Ait Pekten Okuliler Üzerine Karşılaştırmalı Histolojik Çalışma
}

\author{
Deniz KORKMAZ1,a, $₫$, İsmail Şah HAREM ${ }^{1, b}$ \\ ${ }^{1}$ Harran Üniversitesi Veteriner Fakültesi Histoloji-Embriyoloji Anabilim Dalı, Eyyubiye Yerleşkesi, Şanlıurfa, TÜRKiYE \\ aORCID: 0000-0002-5739-3824; bORCID: 0000-0002-5947-4118
}

\begin{tabular}{ccc}
\hline Geliş Tarihi/Received & Kabul Tarihi/Accepted & Yayın Tarihi/Published \\
28.12 .2020 & 09.02 .2021 & 30.06 .2021 \\
\hline
\end{tabular}

Öz

Yapılan çalışmada farkıı kanatlı türlerine (baykuş, bıldırcın, devekuşu ve Pekin ördeği) ait pekten okuli örneklerinin ışık mikroskobik olarak incelenmesi amaçlanmıştır. Bu amaçla alınan doku örnekleri formolde tespit edilerek parafinde bloklanmış, rutin histolojik işlemlerden sonra Masson's trikrom tekniği ile boyanmış ve incelenmiştir. Yapılan incelemeler sonucu tüm kanatlı türlerinde pekten okuliyi oluşturan temel yapı aynı olsa da pektende pili sayılarının, kan damarları çapı ve yerleşiminin, melanosit miktar ve yerleşiminin farklılıklar gösterdiği tespit edilmiştir. Bu verilere göre en fazla pili sayısına sahip devekuşlarının aynı zamanda en geniş damar çapına sahip olduğu belirlenmiştir. Bununla birlikte pili sayısı en az olan baykuşların daha küçük çaplı damarlara sahip olduğu gözlemlenmiştir. Tüm bu veriler pekten okulinin hayvan türüne göre yapısal farklılıklarının olduğunu göstermektedir. Bu yapısal farklııkların hayvanların büyüklükleri, avlanma ve beslenme çeşitlilikleri ile ilgili olduğu, bu konu ile ilgili daha kapsamlı çalışmalar yapılması gerektiği düşünülmektedir.

Anahtar Kelimeler: Pekten oculi, ışık mikroskop, baykuş, bıldırcın, devekuşu, Pekin ördeği

Comparative Histological Study on Pecten Oculi of Different Poultry Species

Abstract

This study aimed to comparatively examine pecten oculi samples of different avian species (owl, quail, ostrich and Pekin duck) by light microscopic technic. Tissue samples taken for this purpose were fixed in formalin, blocked in paraffin, passed through routine histological procedures, stained with Masson's trichrome method and examined. As a result of the examinations, it has been determined that although the basic structure forming the pecten oculi is the same in all poultry species, the number of pleats, the diameter and location of the blood vessels, the amount and location of melanocytes differ. According to these data, it was determined that ostriches with the highest number of pleats also have the largest vein diameter. However, it has been observed that owls with the least number of pleats have smaller diameter vessels. All these data show that pecten oculi has structural differences according to animal species. It is thought that these structural differences are related to the size of animals, hunting and feeding diversity, and more comprehensive studies should be done on this subject.

Key Words: Pecten oculi, light microscopy, owl, quail, ostrich, Pekin duck

\section{GiRiş}

Tüm vertebralılardan farklı olarak kanatlı retinası tamamen avaskülerdir (1). Retina pekten okuli olarak adlandırılan ve yalnızca kanatlı gözünde bulunan bir yapı tarafından beslenir Pektenin retinayı beslenme dışında birçok farklı fonksiyonu da bulunduğu düşünülmektedir (2).

Morfolojik olarak, pekten okuli koni tipi (Kiwi) pervane tipi (devekuşu) pili tipi (diğer tüm kuş türleri) olmak üzere üç sınıfa ayrılmıştır (3). Temelde üç sınıfa ayrılsalar da her kanatlı türünde farklı büyüklüklerde ve farklı sayıda piliye sahip pekten okuliler bulunmaktadır $(4,7)$. Tüm kanatlılarda pekten okuli; nervus optikusun retinaya giriş bölgesinden vitreusa doğru uzanır, geniş bir temel üzerine oturur, çok sayıda kapillar damara ve melanositlere sahiptir $(8,10)$. Ayrıca bazı kanatlı türlerinde pekten okuli üzerinde hiyalosit adı verilen hücreler bulunduğundan da bahsedilmektedir $(11,12)$.
Devekuşu; New Zellanda kiwi, Avusturalya emu, Güney Amerika rheas, Yeni Gine cassowaries ile akrabadır. Yaşayan kara hayvanları içinde en büyük gözlere sahip canlı olduğu bildirilmektedir. Büyük gözlerin avcıları uzak mesafelerden bile görmeye yardımcı olduğu ve gözün şeklinin gözü güneş ışınlarından koruduğu düşünülmektedir. Diurnal olan bu hayvanlar aydınlık gecelerde de aktif olabilirler. Pekin ördeği; kaz ve kuğu gibi su kuşları ailesine dahil olmakla beraber küçük yapılı canlılardır. Diurnal olan bu hayvanlar küçük balık ve böceklerle beslenirler. Nocturnal olan baykuşlar binocular ve keskin bir görüşe sahip, iri vücutlu ve büyük gözlü yırtıcı kuşlardır. Gözlerini değil kafalarını hareket ettirirler ve yalnızca uzaktaki nesnelere odaklanırlar. Hindi, tavuk gibi kuşların dahil olduğu Galliformes ailesine dahil olan bıldırcınlar diurnaldırlar ve tohumlar ile küçük omurgasızlarla beslenirler (13). 
Yapılan çalışma ile baykuş, bıldırcın, devekuşu ve Pekin ördeğine ait pekten okuli örnekleri incelenerek aralarındaki farklılığın ortaya konulması amaçlanmaktadırBu çalışmanın, kanatlı türleri arasındaki pekten okuli farklılıklarının nereden kaynakladığı ile ilgili fikir verebileceği ve bu konu ile ilgili diğer çalışmalara kaynak sağlayabileceği düşünülmektedir.

\section{MATERYAL VE METOT}

Çalışmada Harran Üniversitesi Veteriner Fakültesi hayvan hastanesine gelen ve kurtarılamayan ölü hayvanlar Harran Üniversitesi Rektörlüğü Hayvan Deneyleri Yerel Etik Kurulu'nun 20/06/2019 tarih ve E.26073 sayılı izni ile kullanıldı. Farklı kanatlı türlerinden (Pekin ördeği, devekuşu, baykuş, bıldırcın) birer adet alınan pekten okuli örnekleri \%10 nötral tamponlu formalin solüsyonunda 24 saat tespit edildikten sonra 24 saat yıkamaya alındı. Rutin doku takip prosedürlerine göre dereceli alkollerden ve ksilolden geçirilen doku örnekleri parafinde bloklandı. Bloklanan bu doku örneklerinden $5 \mu \mathrm{m}$ kalınlığında alınan seri kesitlere Masson's trikrom boyama tekniği uygulandı $(14,15)$. Boyanan preparatlar araştırma mikroskobunda (Olympus BX51) incelenerek fotoğraflandı. Ayrıca boyanan preparatlardan her kanatlı türü için 6 adet seri kesit rastgele seçildi ve seçilen bu kesitlerden rastgele 6 bölgede (her bir hayvan için toplamda 36 ayrı bölgede) primer ve sekonder damar çapları cellSens image software analysis program (Olympus DP73) kullanılarak ölçüldü ve fotoğraflandı.

\section{BULGULAR}

Baykuşta pekten okuli yaklaşık 8-9 adet piliden oluşmaktaydı. Pekten bazalinde hem melanositler hem de yoğun kan damarları bulunmaktaydı. Pekten pilileri incelendiğinde primer damarların kıvrımların ortasında, sekonder damarların ise periferde yer aldığı gözlemlendi (Şekil 1-A). Pililerde yoğun olarak rastlanan melanositler ise damarların etrafını sarmaktaydı. Melanositler pekten pililerinin periferinde daha da yoğunlaşmaktaydı. ışık mikroskopta hyalositlere rastlanmadı (Şekil 2-A). Primer damar çapı $38.86 \mu \mathrm{m}$ iken, sekonder damar çapı $17.28 \mu \mathrm{m}$ olarak ölçüldü (Şekil 3-A) (Tablo 1).
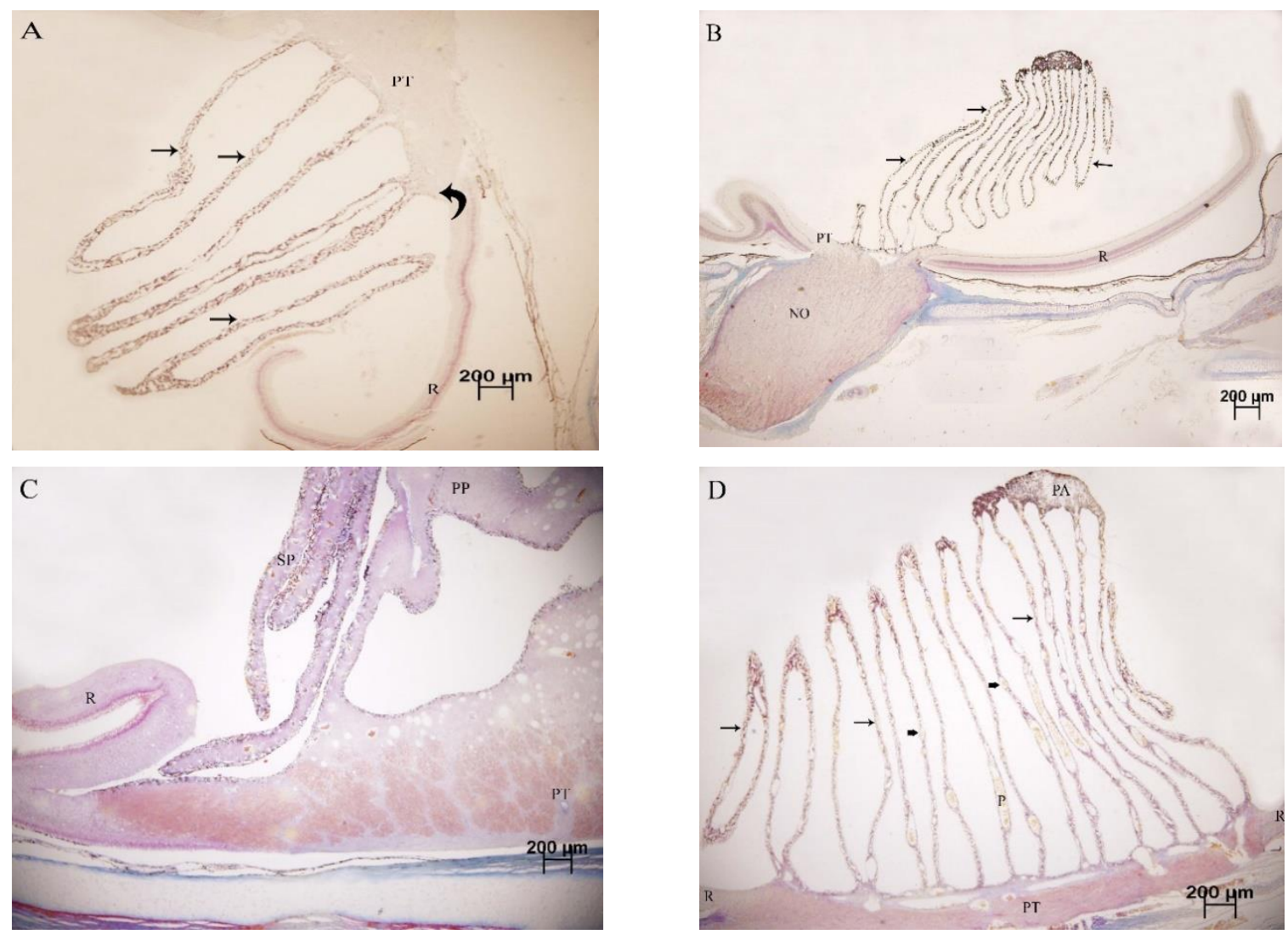

Şekil 1: A: Baykuş Pekten, B: Bıldırcın Pekten, C: Devekuşu Pekten, D: Pekin Ördeği Pekten PT: Pekten Tabanı, R: Retina, NO: Nervus Optikus, PA: Pekten Apikali, PP: Primer Pili, SP: Sekonder Pili, Ok: Pekten pili, Kıvrımlı ok: Retina pekten geçişi. Kalın ok: Pekten damarları Masson'un üçlü boyaması.

Tablo 1. Farklı kanatlı türlerine ait primer ve sekonder damar çapları $(\mu \mathrm{m})$

\begin{tabular}{|c|c|c|c|c|c|c|c|}
\hline PEKIN ÖRDEK & & VEKUŞU & & YKUŞ & & DIRCIN & \\
\hline $\mathrm{PR}(\mu \mathrm{m})$ & SK $(\mu \mathrm{m})$ & $\mathrm{PR}(\mu \mathrm{m})$ & SK $(\mu \mathrm{m})$ & $\mathrm{PR}(\mu \mathrm{m})$ & SK $(\mu \mathrm{m})$ & $\mathrm{PR}(\mu \mathrm{m})$ & SK $(\mu \mathrm{m})$ \\
\hline ort & ort & ort & ort & ort & ort & ort & ort \\
\hline 51.03472 & 19.6075 & 58.73472 & 32.01722 & 38.86972 & 17.28 & 35.73722 & 15.68444 \\
\hline
\end{tabular}

PR: Primer damar çapı $(\mu \mathrm{m})$ SK: sekonder damar çapı $(\mu \mathrm{m})$ 
Korkmaz ve Harem, Dicle Üniv Vet Fak Derg 2021;14(1):7-10

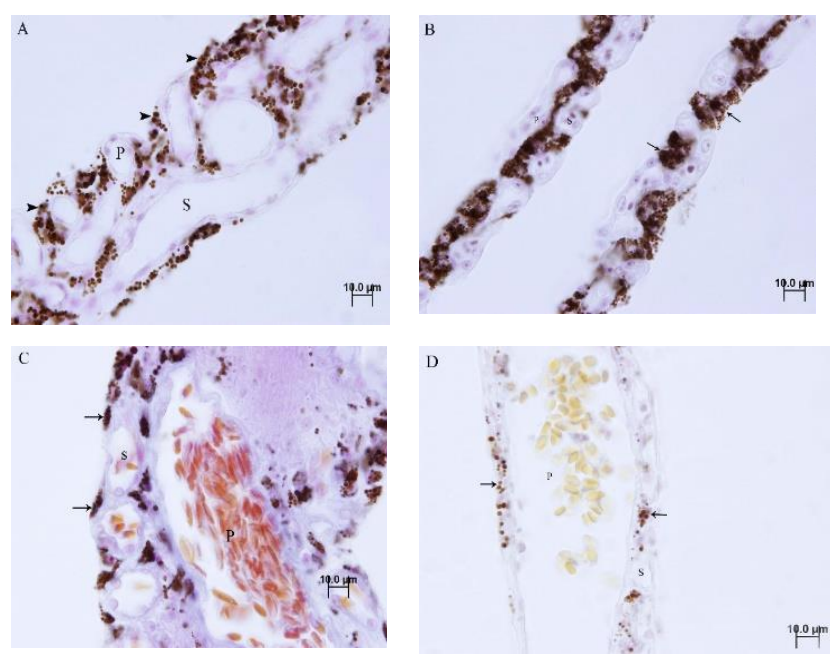

Şekil 2: A: Baykuş Pekten, B: Bıldırcın Pekten, C: Devekuşu Pekten, D: Pekin Ördeği Pekten P: Primer Damar, S: Sekonder Damar, Ok: Melanosit. Ok başı: Vitreo-pekteneal membrane Masson'un üçlü boyaması
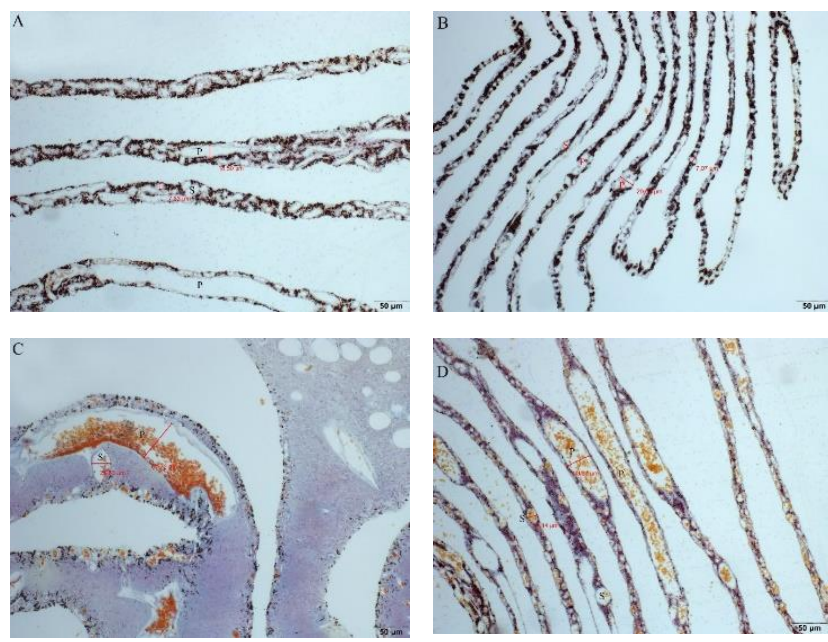

Şekil 3: A: Baykuş Pekten, B: Bıldırcın Pekten, C: Devekuşu Pekten, D: Pekin Ördeği Pekten P: Primer Damar, S: Sekonder Damar. Masson'un üçlü boyaması.

Bıldırcında ise pekten yaklaşık 19 adet piliden oluşmaktaydı. Pekten bazalinde kan damarları yanında yoğun melanosit yerleşimi gözlendi. Melanositlerin pekten bazal tabakasına yayılmış olduğu gözlendi. Bazalden gelen primer damarlar pekten pililerine doğru uzanmaktaydı. Primer damarlar pekten pililerinin ortasında, sekonder damarlara ise periferde yer almaktaydı (Şekil 1-B). Melanositlerin damarların etrafında ve pililerin merkezinde yerleşmiş olduğu gözlendi (Şekil 2-B). Pekten pililerinin bazalden ayrıldıktan sonra vitreusa doğru uzandığı, vitreusta köprü yaptığı ve geri dönerek bazale bağlandığı belirlendi. Primer damar çapı $35.73 \mu \mathrm{m}$ iken, sekonder damar çapı $15.68 \mu$ m olarak hesaplandı (Şekil 3-B) (Tablo 1). Bıldırcın pekteninde de hyalositlere rastlanmadı.

Devekuşunda pekten okuli yaklaşık 20-21 adet piliden oluşmaktaydı. Pekten okulinin oturduğu bazal kısım oldukça geniş bir alanı kaplamaktaydı. Devekuşunda pekten oculi, nervus optikusun vitreusa açıldığı kısımda; retinanın kopuntuya uğradığı iki ucu arasında yer almaktaydı. Bazalinde yoğun kan damarlarına rastlanırken melanositlere rastlanmadı.
Farklı Kanatlı Türlerine Ait Pekten Okuliler Üzerine Karşıllaştırmalı Histolojik Çalışma

Pektenin geniş bir temel üzerinde vitreusa doğru uzanarak kollara ayrıldığı görüldü. Bazalden itibaren primer, sekonder ve tersiyer kolların varlığı gözlemlendi (Şekil 1-C). Bazalde rastlanmayan melanositlerin pililerde ortaya çıktığı belirlendi. Pekten pililerinin orta kısmında ise primer ve sekonder damarlar bulunmaktaydı. Devekuşu pekteninde ışık mikroskobik incelemelerde hyalositlere rastlanmadı (Şekil 2-C). Primer damar çapı $58.73 \mu \mathrm{m}$ iken, sekonder damar çapı 32.01 $\mu \mathrm{m}$ olarak hesaplandı (Şekil 3-C) (Tablo 1).

Pekin ördeğinde pekten okulinin yaklaşık 18-20 adet piliden oluştuğu saptandı. Pektenin oturduğu geniş bazal kısımda farklı büyüklüklerde kan damarlarına rastlandı. Bununla birlikte melanositlerin bazalde sadece pekten pililerinin başladığı bölgede ortaya çıktığı, bazale yayılmadığı gözlendi (Şekil 1-D). Pekten bazalinden vitreusa doğru uzanan pililerde bir iki adet uzunlamasına seyreden büyük kan damarları (Primer damar) ve bunların aralarını dolduran çok sayıda küçük kan damarları (Sekonder damar) gözlendi. Bu kan damarlarının arasında, vitreus bölgesinde daha yoğun olmak üzere çok sayıda melanositlere rastlandı. Işık mikroskobik incelemelerde hyalositlere rastlanmadı (Şekil 2-D). Primer damar çapı $51.034 \mu \mathrm{m}$ iken, sekonder damar çapı $19.60 \mu \mathrm{m}$ olarak hesaplandı (Şekil 3-D) (Tablo 1).

\section{TARTIŞMA VE SONUÇ}

Yapılan çalışmalarda devekuşunda bir adet primer lamel, 1619 adet sekonder lamel, sekonder lamellerin bazılarında 2-3 tersiyer lamel olduğu (16), Emu 'da 3-4 büyük pili (17) Baladi ördeğinde 14-15 (18), ördekte 12 (19), bayağı peçeli baykuşta 7-8 (5), küçük puhuda 5-6 (20) çoban aldatanda 45 (21) ve bıldırcında 18 (22) adet pili olduğu bildirilmiştir. Yapılan çalışmada baykuş, bıldırcın, devekuşu ve pekin ördeğinde sırasıyla 8-9, 19, 20-21, 18-20 adet pili bulunduğu belirlenmiştir. Bu bulgu da genel olarak büyük kafaya sahip kanatıların pekten pili sayılarının daha fazla olduğunu göstermektedir.

Pekten okulide bulunan damarlar üzerine yapılan çalışmalarda, pekten okulide hayvan türlerine göre farklı büyüklüklerde damarlar olduğu bildirilmiştir. $(5,19,23)$. Yaptığımız çalışmada yer alan tüm kanatlı türlerinde iki farklı büyüklükte damar olduğu görüldü. Bu damarlar baykuş, bıldırcın, devekuşu ve pekin ördeğinde primer ve sekonder olarak sırasıyla 38-17, 35-15, 58-32 ve 51-19 $\mu$ m olarak hesaplandı (Tablo 1). Bu bulgular da büyük kafaya sahip, pili sayısı fazla kanatlılara ait pekten okulilerde daha geniş çaplı primer ve sekonder damarlar olduğunu göstermektedir. Damar çaplarındaki bu değişim pekten okulinin retinanın beslenmesinde rol aldığı bilgisini destekler niteliktedir.

Tüm kanatlı pektenlerinin, damar ve melanositlerden oluştuğu bildirilse de $(7,18,21)$ hayvan türlerine göre damarların yerleşimi ve melanosit yoğunluğu farklılık göstermektedir. Örneğin, güvercinde az sayıda melanosite rastlanırken (7), dalgıçkuşunda yoğun melanositlerin varlığından bahsedilmektedir (24). Yapılan çalışmada melanositler en yoğun olarak baykuşta pekten pililerinin periferinde, bıldırcında damarların etrafında ama çoğunlukla pililerin merkezinde ve apekste, devekuşunda az sayıda yine 
damarların etrafında pekin ördeğinde ise kan damarlarının etrafında ama en yoğun olarak pekten apeksinde bulunduğu görüldü. Pekten melanositlerinin yerleşimi ve miktarının hayvan türüne göre değişmesi canlının beslenme ve avlanma şekline göre pekten yapılarının değişiklik gösterdiği tezini desteklemektedir.

Tüm kanatlılarda pekten okuli vitreo-pekteneal sınırlayıcı membran ile çevrelenmiş olsa da $(5,7,17)$ hepsinde hyalosit adı verilen makrofaj benzeri hücrelere rastlanmamıştır $(25,26)$. Yapılan çalışmada da baykuş, bıldırcın, devekuşu ve Pekin ördeğinde ışık mikroskobik incelemede hyalosite rastlanmamıştır.

Yapılan bu karşılaştırmalı çalışma sonucunda elde edilen veriler, pekten okulinin kanatlı türüne göre farklı özellikler gösterdiğini ve bu farklılıkların canlının yapısal özelliklerine, beslenme ve avlanma şekline bağlı olabileceği fikrini desteklemektedir.

\section{KAYNAKLAR}

1. Montoyo YG, Garcia M, Yolanda S. (2018). Light and Electron Microscopic Studies on the Retina of The Booted Eagle (Aquila pennata). Zoomorphol. 137: 177-190.

2. Brach V. (1977). The functional significance of the avian pecten: a review. Condor. 79: 321-327.

3. Meyer DB. (1977). The avian eye and its adaptations. In: Handbook of Sensory Physiology. Vol V1115. The Visual System in Vertebrates. Crescitelli F. (ed). Springer-Verlag. Berlin. Pp 549612.

4. Gezer İnce N, Onuk B, Kabak YB, Alan A, Kabak M. (2017). Macroanatomic, Light and Electron Microscopic Examination of Pekten Oculi in the Seagull (Larus canus). Microsc Res Tech. 80: 787-792.

5. Yılmaz B, Korkmaz D, Alan A, Demircioğlu i, Akbulut $Y$, Oto C. (2017). Light and Scanning Electron Microscopic Structure of the Pecten Oculi in the Common Barn Owl (Tyto alba). Kafkas Univ Vet Fak Derg. 23 (6): 973-979

6. Mishra P, Meshram B. (2019). Scientific Perspective on Morphological Feature of Pecten Oculi and Their Functional Principles on Apparatus of Vision in Guinea fowl (Numida meleagris). Birds Int J Adv Res. 7(4): 1061-1079.

7. Korkmaz D. (2017). Güvercinde (Columbidae columbiformes) Pekten Okulinin Histomorfolojik Yapısı. Harran Üniv Vet Fak Derg. 6(1): 90-94.

8. Braekevelt CR. (1993). Fine Structure of the Pecten oculi in the Great Horned. Owl. Histol Histopathol. 8: 9-15.

9. Rahman ML, Lee E, Aoyama M, Suqita S. (2010). Light and Electron Microscopy Study of the Pecten Oculi of the Jungle Crow (Corvus macrorhynchos). Okajimas Folia Anat Jpn. 87: 75-83.

10. Kleyn E. (2017). A Comparative Morphological and Morphometric Study of the Musculi Bulbi Oculi and Apparatus Lacrimalis in the Ostrich (Struthio camelus) and Emu (Dromaius novaehollandiae). Master Thesesis Department of Anatomy and Physiology, Faculty of Veterinary Science, University of Pretoria, p:7 Republic of South Africa.

11. Korkmaz D, Kum S. (2016). Investigation of the Antigen Recognition and Presentation Capacity of Pectineal Hyalocytes in the Chicken (Gallus gallus domesticus). Biotech Histochem. 91 (3): 212-219.
12. Henis MEG, Ahmed AK, Ibrahim IA, Saleh AM. (2015). Light and Electron Microscopical Studies on the Hyalocytes of Turkey (Meleagris Gallopavo). J Adv Vet Res. 5 (1): 8-13.

13. http://www.bird.com. Erişim tarihi: 22.12.2020

14. Crossman G. (1937). A Modification of Mallory's Connective Tissue Stain with a Discussion of the Principles Involved. Anat Rec. 69: 33-38.

15. Denk H. Kunzele H, Plenk H, Ruschoff J, Sellner W. (1989). Romeis Microscopische Tecnic, 17, Neubearbeitete Auflage. Urban und Schwarzenberg, München, Wien, Baltimore. pp. 439450.

16. Kiama SG, Maina JN, Bhattacharjee J, Mwangi DK, Macharia RG, Weyrauch KD. (2006). The Morphology of the Pecten Oculi of the Ostrich (Struthio camelus). Ann Anat. 188: 519-528.

17. Braekevelt CR. (1998). Fine Structure of the Pecten Oculi of the Emu (Dromaius novaehollandiae). Tissue Cell. 30 (2): 157-165.

18. Moselhy AAA, El-Hady E. (2019). Gross, Histochemical and Electron Microscopical Characterization of the Pecten Oculi of Baladi ducks (Anas boschas domesticus). J Adv Vet Res. 6(4): 456-462.

19. Dayan MO, Özaydin TA. (2013). Comparative Morphomertical Study of the Pecten Oculi in Different Avian Species. The Scien World J. Article ID: 968652

20. Kiama SG, Maina JN, Bhattacharjee J, Weyrauch KD. (2001). Functional Morphology of the Pecten Oculi in the Nocturnal Spotted Eagle Owl (Bubo bubo africanus) and the Diurnal Black Kite (Milvus migrans) and Domestic Fowl (Gallus gallus domesticus): A comparative study. J Zool. 254: 521-528.

21. Braekevelt CR. (1984). Electron Microscopic Observations on the Pecten of the Nighthawk (Chordeiles minor). Ophthalmol. 189:211-220.

22. Pourlis AF. (2013). Scanning Electron Microscopic Studies of the Pecten Oculi in the Quail (Coturnix coturnix Japonica). Anat Res Int. Article ID: 65061.

23. Kiama SG, Bhattacharjee J, Maina JN, Weyrauch KD. (1997). Surface Specialization of the Capillary Endothelium in the Pecten Oculi of the Chicken and Their Overt Roles in Pectineal Haemodynamics and Nutrient Transfer to the Inner Neural Retina. Acta Biol Hun. 48: 473-483.

24. Braekevelt CR. (1986). Fine Structure of the Pecten Oculi of the Common Loon. Can J Zool. 64(10): 2181-2186.

25. Braekevelt CR. (1994). Fine Structure of the Pecten Oculi in the American Crow. Anat Histol Embryol. 23: 357-366.

26. Smith BJ, Smith SA, Braekevelt CR. (1996). Fine Structure of the Pecten Oculi of the Barred Owl. Histol Histopathol. 11(1): 8996.

\footnotetext{
Sorumlu Yazar: Deniz KORKMAZ

Harran Üniversitesi Veteriner Fakültesi Histoloji-Embriyoloji Anabilim Dalı, Eyyubiye Yerleşkesi, Şanlıurfa, TÜRKiYE E-posta: denizkorkmaz@harran.edu.tr
} 